\title{
Size Effects on Residual Stress and Fatigue Crack Growth in Friction Stir Welded 2195-T8 aluminium Part II: Modelling
}

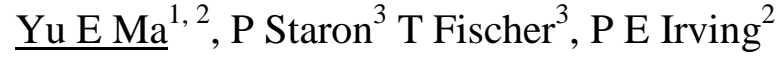 \\ ${ }^{1}$ School of Aeronautics, Northwestern Polytechnical University, China; ${ }^{2}$ Damage \\ Tolerance Group, School of Applied Science, Cranfield University, UK; ${ }^{3}$ Institute of \\ Materials Research, Geesthacht, Germany
}

\begin{abstract}
:
The use of residual $\mathrm{K}\left(\mathrm{K}_{\text {res }}\right)$ approaches for prediction of fatigue crack growth rates in residual stress fields was studied. Finite element models of the samples were built and the measured residual stress data put into the model. The virtual crack closure technique (VCCT) was used to calculate $K_{\text {res }}$ (stress intensity factor from residual stress) together with its changes with crack length using data from the part I paper. Local $K_{\text {res }}$ values were used to calculate effective $R$ values. $K_{\text {op }}$ and $\Delta K_{\text {eff }}$ values throughout the crack path in the weld were calculated. The master curve approach was used to relate these to corresponding values for crack growth rates. Predicted crack growth rates were compared with experimental results. Changes in crack growth rate found as the crack grows through the weld can successfully be predicted via application of this closure based model. Agreement between predictions and experimental data was best for tensile residual stress fields and was not as exact in compression. Possible reasons for this discrepancy are discussed.
\end{abstract}

Keywords: Friction stir weld; Residual stress; Fatigue crack growth; Closure model 


\section{NOMENCLATURE}

$$
\begin{aligned}
a & =\text { crack length } \\
K & =\text { stress intensity factor } \\
K_{\text {res }} & =\text { stress intensity factor from residual stress } \\
N & =\text { cycle (fatigue load) } \\
d a / d N & =\text { crack growth rate } \\
G & =\text { strain energy release rate } \\
F_{j} & =\text { the reaction force on } j \text { node } \\
u_{i} & =\text { the total displacement from } i \text { node } \\
t & =\text { thickness of samples } \\
\Delta c & =\text { element size } \\
E & =\text { the Young's modulus (modulus of elasticity) } \\
R_{\text {nom }} & =\text { applied load R ratio } \\
R_{\text {effective }} & =\text { R ratio with the presence of residual stress } \\
\Delta K_{\text {eff }} & =\text { the effective stress intensity factor range } \\
S_{o} & =\text { the crack opening stress } \\
S_{\max }, S_{\min } & =\text { the applied maximum, minimum stress }
\end{aligned}
$$

\section{Introduction}

In the past few years it has been realised that calculation of stress intensity associated with a crack in a residual stress field is a fruitful way of accounting for the effects of residual stress fields on fatigue crack growth [1-5]. There are however a number of different techniques to calculate or otherwise obtain $K_{\text {res }}$ values for a crack growing in a varying residual stress field such as might be associated with a weld. Current techniques are as follows. The cut compliance technique [2-5], for instance uses slitting to cut the sample [5]. The residual stress distribution can then be calculated via discretisation, taking account of the weight function from $K_{r e s}$. Another method uses weight functions, as suggested by Buechner [6] using one of the other functions for different sample geometries produced by Glinka [7]. The finite element method [8, 
9] can be applied after residual stress profiles have been measured. For the weight function method, the equation to be solved for $\mathrm{K}_{\mathrm{res}}$ is:

$$
K_{r e s}=\int_{a_{0}}^{a} h(x, a) \cdot \sigma_{r e s}(x) \cdot d x
$$

where $h(x, a)$ is the weight function, available for several geometries and conditions [7]. $\sigma_{r e s}(x)$ is the residual stress distribution before crack propagation. However, if redistributions of residual stress arising from crack propagation are not taken into account, errors occur in calculation of $K_{\text {res }}$. This has been pointed out by a number of researchers e.g. $[8,10,11]$.

For calculation of the effect of changes in $K_{\text {res }}$ on fatigue crack growth rates, two complementary approaches can be used: one is the superposition approach $[2,12,13]$; the other uses the crack closure model $[1,9,11,15-18]$, as originally proposed by Elber [18], and modified by Newman [15].

In the superposition approach, shown in Fig.1, the cyclic maximum and minimum stress intensity factors $K_{\max , t o t}, K_{\min , t o t}$ derived from superposition of both external and residual stresses are given by:

$$
\begin{aligned}
& K_{\text {max, tot }}=K_{\text {max, app }}+K_{r e s} \\
& K_{\text {min, tot }}=K_{\text {min, app }}+K_{r e s}
\end{aligned}
$$

The stress intensity factor range and effective stress ratio $\mathrm{R}_{\mathrm{eff}}$ are calculated:

$$
\begin{aligned}
\Delta K & =K_{\max , \text { tot }}-K_{\min , \text { tot }} \\
& =\left(K_{\max , a p p}+K_{r e s}\right)-\left(K_{\min , a p p}+K_{r e s}\right) \\
& =K_{\max , a p p}-K_{\min , a p p}=\Delta K_{a p p} \\
& R_{\text {eff }}=\frac{K_{\min }+K_{r e s}}{K_{\max }+K_{r e s}}
\end{aligned}
$$

For $\mathrm{K}_{\mathrm{res}}=$ zero $\mathrm{R}_{\mathrm{eff}}$ will be identical to $\mathrm{R}_{\mathrm{app}}$ the $\mathrm{R}$ ratio of the externally applied loading. 
In this approach, the stress intensity factor range $\Delta K$ is independent of residual stress and of $\mathrm{K}_{\mathrm{res}}$, however the effective stress ratio $R_{\text {eff }}$ is significantly affected. Then fatigue crack growth rates are a function of $\Delta K_{\text {app }}$ and $R_{\text {eff: }}$ :

$$
\frac{d a}{d N}=f\left(\Delta K_{a p p}, R_{e f f}\right)
$$

$\mathrm{K}_{\text {res }}$ and $\mathrm{R}_{\text {eff }}$ will change as the crack grows through the residual stress field and the growth rate at each crack length can be obtained either from relevant experimental da/dN data obtained at $R_{\text {eff }}$ or derived from da/dN at other values of $\mathrm{R}$ by use of the Forman [19] or other expressions. The experimental da/dN data easiest to obtain will be obtained on parent plate, but ideally should be material with the same strength and microstructure as the weld and HAZ without the residual stresses.

For the crack closure approach, shown in Fig.2, the effective stress intensity factor $\Delta \mathrm{K}_{\mathrm{eff}}$, the range of the applied load cycle for which the crack is open, can be calculated [15] as:

$$
\begin{aligned}
\Delta K_{e f f} & =U \cdot \Delta K_{a p p} \\
U & =\frac{1-S_{\text {open }} / S_{\max }}{1-R_{\text {eff }}} \\
\Delta K_{\text {eff }} & =K_{\text {max }, \text { tot }}-K_{\text {open }} \\
\frac{d a}{d N} & =g\left(\Delta K_{e f f}\right)
\end{aligned}
$$

where $S_{\text {open }} / S_{\max }$ was given by Newman [15], as shown in equation (12-17) thereafter.

Following Newman [15], equations (6)-(7), the different curves of $\frac{d a}{d N}$ versus $\Delta K_{a p p}$ measured at different $\mathrm{R}$ ratios can be replaced by a single "Master" curve of $\frac{d a}{d N}$ 
versus $\Delta K_{\text {eff }}$. The master curve of $\Delta K_{\text {eff }}$ vs. da/dN can be obtained [15] from 3 crack growth rate curves measured at different tensile $\mathrm{R}$ values. For samples containing a residual stress, values of $R_{\text {eff }}$ and $\Delta K_{\text {eff }}$ can be calculated from $K_{\text {res }}$ as described above and then related to $\frac{d a}{d N}$ via the master curve.

Both approaches use calculations of $\mathrm{K}_{\text {res }}$ to derive changes in crack tip $\mathrm{R}$ ratio as the crack tip moves through the residual stress field. However the two approaches differ in their calculation of growth rates in that the superposition technique uses experimental crack growth rate data from parent plate at the relevant $\mathrm{R}$ values , whereas in the closure approach the derived master curve can be applied to all values of $R_{\text {eff }}$, including negative ones, from data from just 3 positive $R$ ratio tests.

However, Lam [8] has shown that there is a factor of four difference in calculated $K_{\text {res }}$ depending on whether redistribution of residual stress with crack growth is considered. Yong [10] and LaRue [11] accurately predicted fatigue life using a crack closure model after considering the redistribution of residual stress. This suggests that predictions of fatigue crack growth rates in residual stress fields should always account for the redistribution of residual stress with crack growth in deriving $\mathrm{K}_{\mathrm{res}}$ values.

In this work finite element models were built using ABAQUS [20] for welded samples of $\mathrm{C}(\mathrm{T})$ and $\mathrm{ESE}(\mathrm{T})$ geometries in three different sizes tested as described in the companion Part I paper [22] Sample geometries and sizes are given in Table I. Half of each geometry was modelled because of symmetries of load. The SIGINI subroutine in ABAQUS can be used to input the initial stress. This subroutine can be programmed by FORTRAN. A FORTRAN program was written to input the 
measured residual stress profiles (see Fig.6-8 in Part I [22]) into finite element models using the SIGNI subroutine. This was the initial step of the analysis.

\section{Balancing and redistribution of residual stresses}

\subsection{Balancing of residual stress fields}

Residual stress fields must be self balanced. The experimental stress profiles shown in figures 6-8 in part I of this work [22], are from discrete measurements along a line within and parallel to the eventual crack plane and are not complete fields. Before the $\mathrm{K}_{\text {res }}$ analysis, a static procedure was used to calculate the equilibrium self balanced stress state for the finite element model. In this step, ABAQUS/Standard was set up to check the stress field for equilibrium and to change the stresses via iteration to achieve equilibrium. For CT and ESET samples, only the stresses perpendicular to the crack plane were applied to the self balance routine. Stresses parallel to this plane were not represented. In placing the experimental residual stress fields into the FE model it was assumed that the same profile for stresses longitudinal to the weld existed at all points normal to the crack plane up to the sample boundary. Because the weld line is parallel to the long axis of the $\operatorname{ESE}(\mathrm{T})$ sample, stresses in this geometry will be largely invariant with distance along the weld until the sample boundary is approached and this assumption is justified.

For CT samples crack growth is along and parallel to the weld line. The residual stresses contributing to crack growth in this case will be perpendicular to the weld line. As fig. $7 \mathrm{~b}$ in [22] shows, these stresses are relatively small ( maximum of 40-50 MPa) and reduce significantly at distances in excess of $20 \mathrm{~mm}$ from the weld line. Hence the assumption of residual stress profiles which do not change with distance away 
from the weld line is not as well justified, in contrast to the situation with $\operatorname{ESE}(\mathrm{T})$ samples.

When residual stresses were put into the model, in both samples some small rebalancing occurred. For $\operatorname{ESE}(\mathrm{T})$ samples these were believed to be partly due to the nearby sample edge free surfaces, and partly due to incompatibilities between measured partially defined fields and the assumed fields in other parts of the samples. The changes arising from rebalancing were greatest in the CT samples; this probably arises as a consequence of the assumptions discussed above.

\subsection{Redistribution of residual stress with crack growth}

After stress rebalancing, a crack was inserted in the FE model and allowed to grow by removing nodes in the model. As the crack grew $K_{\text {res }}$ was calculated by the virtual crack closure technique (VCCT) [21] from the finite element model. $K_{\text {res }}$ values in each sample size were compared. Differences of $K_{\text {res }}$ in specimens of different size will arise from differences in residual stresses. The $\mathrm{R}_{\text {eff }}$ changes with crack length were calculated, and then $\Delta K_{\text {eff }}$ was calculated using equation (6-9). Using the crack growth rate data from the parent plate shown in part I, the master curve plot of $\Delta \mathrm{K}_{\mathrm{eff}}$ $\mathrm{Vs} \mathrm{da} / \mathrm{dN}$ was calculated. Crack growth rates for $\Delta \mathrm{K}_{\mathrm{eff}}$ were derived from this curve.

The residual stress field from a 148x40 ESET sample after equilibrium calculations but before a crack is introduced, is shown compared to the measured residual stress data in Fig.4. For this sample, the solid line connecting the square points is the measured residual stress profile in the uncracked state, while the continuous line without data points shows the same field after balancing. To balance the measured 
tensile stress data, the region without experimental data between the notch root and the first experimental point should contain a local compressive field of -128 $\mathrm{MPa}$. Introduction of the crack modifies this initial field and at a length of $15.0 \mathrm{~mm}$ significant redistribution of the original field is predicted, although the compressive peak in stress immediately ahead of the crack tip remains large. Double stress peaks are still predicted on either side of the weld line but the first one is much reduced. Crack growth to 20 and $30 \mathrm{~mm}$ length further modifies and reduces calculated residual stresses to trivial levels as the stress field further redistributes..

In Fig.5, for the $\mathrm{C}(\mathrm{T})$ sample $125 \times 120 \mathrm{~mm}$, the solid line with diamond points is the measured residual stress on the uncracked sample, while the solid line without points shows the calculated residual stress after balancing and before cracking. As was the case for the ESET sample in figure 4, the balanced compressive residual stress at the uncracked notch tip was large, in this case about -210 MPa. With crack growth to 65 , 85 and $115 \mathrm{~mm}$, calculated balanced compressive and tensile residual stresses are reduced with the same trends as for the ESET sample. Larger CT samples showed the same trends.

\section{Calculation of $K_{\text {res }}$ from residual stress distributions}

Finite element analysis was used to calculate the stress intensity factor $K_{\text {res }}$ from residual stress by using ABAQUS. The models were built. using Quadrilateral shell elements around the notch tip and along the crack lines. The element size was 0.05 $\mathrm{mm}$; triangular elements were used in the transitional area and elements with four nodes in the far field with the edge of $2 \mathrm{~mm}$ length in order to save run time. Rigid elements were used to avoid overlapping material due to over-closure effects from the compressive residual stress. In all finite element models contact elements were used to simulate the applied pin loads. The virtual crack closure technique (VCCT) [21] 
was used for calculating strain energy release rate for unit sample thickness with the formulation:

$$
G=\frac{F_{j} u_{i}}{2 t \Delta c}
$$

where $F_{j}$ is the reaction force on $j$ node; $u_{i}$ is the total displacement from $i$ node; $t$ is thickness of samples and $\Delta c$ is element size, see Fig.6.

For plane stress, the relation between the strain energy release rate and stress intensity factor (SIF) is as follows:

$$
\begin{aligned}
& G=\frac{K^{2}}{E} \quad(\text { Plane stress) } \\
& G=\frac{(1-v) K^{2}}{E} \quad \text { (Plane strain) }
\end{aligned}
$$

If residual stresses are input to this model, $K_{\text {res }}$ can be derived from equations (10) and (11).

\section{1 $K_{r e s}$ and $R_{e f f}$ in ESE(T) samples}

Following equations (4), (10) to (11), $K_{\text {res }}$ and $R_{\text {eff }}$ were calculated. Fig.7 (a) shows residual stress profile and $K_{\text {res }}$ for the smallest ESET sample. It is clear that residual stress has a double peak of about 40.0 MPa and 28.0 MPa at crack lengths of about $16.0 \mathrm{~mm}$ and $29.0 \mathrm{~mm}$ respectively, while $K_{\text {res }}$ has a double peak as well about -1.5 $\operatorname{MPa} \sqrt{m}$ and $0.2 \operatorname{MPa} \sqrt{m}$ at about $19.0 \mathrm{~mm}$ and $33.0 \mathrm{~mm}$, a longer crack length than the peaks in residual stress.

Fig.7 (b) shows a comparison of the nominal and the effective $\mathrm{R}$ ratio $R_{\text {eff }}$ for this test sample for nominal $\mathrm{R}$ ratios of 0.1 and 0.6 . For the nominal $\mathrm{R}=0.1, R_{\text {eff }}$ starts from 
-0.8 then attains -0.9 at a crack length of around $10.5 \mathrm{~mm}$. The $R_{\text {eff }}$ then steadily increases with increasing crack length tending to $\mathrm{R}_{\mathrm{eff}}=0.1$ at a crack length around $30.0 \mathrm{~mm} . K_{\text {res }}$ totally changed the curve of $R_{\text {eff }}$. For the nominal R ratio of 0.6 , $R_{\text {eff }}$ starts from 0.5 , then tends to 0.6 at $18.0 \mathrm{~mm}$ and is constant with increasing crack length after this. For this sample experiments [22] show that residual stress has significantly more effect on crack growth rate for a nominal $\mathrm{R}=0.1$ than for a nominal $\mathrm{R}=0.6$. This is shown in Fig.9 of part I, [22]. This explains why it is difficult to initiate a pre-crack under the load $\mathrm{R}$ ratio 0.1 . For the larger sample, such as $185 \times 50$ $\mathrm{mm}$ and $370 \times 100 \mathrm{~mm}$, the compressive residual stress is larger still than in the smallest $148 \times 40 \mathrm{~mm}$ samples and fatigue cracks could not be initiated and grown at $\mathrm{R}=0.1$. Crack growth occurred in these samples at $\mathrm{R}=0.6$ only.

Following equations (4), (10) to (11), $K_{\text {res }}$ and $R_{\text {eff }}$ in all three ESE(T) sample sizes at nominal $\mathrm{R}$ of 0.6 were calculated and are compared in Fig.8a and b. Fig. 8a shows the changes in $\mathrm{K}_{\mathrm{res}}$ for cracks growing across the three sample widths of 40, 50 and 100 mm. Sample widths are represented as distances from the weld centreline; the smallest sample width will be from -20 to $+20 \mathrm{~mm}$, the middle from -25 to $+25 \mathrm{~mm}$, and the largest from -50 to $+50 \mathrm{~mm}$. The calculated $\mathrm{K}_{\mathrm{res}}$ lines begin just ahead of the notch tip for each sample. $K_{\text {res }}$ values in each sample start negative and move into tensile (positive) values with increasing crack length. Positive values of $\mathrm{K}_{\mathrm{res}}$ are achieved at crack tip locations 8-10 $\mathrm{mm}$ from the weld centre line in all sample sizes. As the crack tip grows beyond the weld, values of $\mathrm{K}_{\text {res }}$ tend towards zero in all samples, again with the longest crack length being required in the largest samples. This reflects the diminution of residual stress as the stress relaxes at long crack lengths. The three sample sizes show big differences in $\mathrm{K}_{\mathrm{res}}$, particularly in the notch region. The biggest samples show the largest values in both tension and compression, 
once again reflecting the relative sizes of the residual stress distributions (shown in Fig.6 of Part. I [22]).

Changes in $R_{\text {eff }}$ with distance from the weld line are shown in Figure $8 b$ where $R_{a p p}$ $=0.6 . R_{\text {eff }}$ tends to $\mathrm{R}_{\mathrm{app}}=0.6$ at crack tip distances of greater than $8-10 \mathrm{~mm}$ beyond the weld line. At smaller crack lengths, when the crack tip is before the weld line, $R_{e f f}$ is much reduced approaching 0.1 in the largest sample and 0.35 and 0.5 in the samples $50 \mathrm{~mm}$ and $40 \mathrm{~mm}$ wide. This reflects the larger negative $\mathrm{K}_{\mathrm{res}}$ in this region. At crack tip positions before $-15 \mathrm{~mm}, \mathrm{~K}_{\mathrm{res}}$ becomes increasingly negative, and $\mathrm{K}_{\min }$ and $\mathrm{K}_{\max }$ reduce further as the crack length is small. When $\left(\mathrm{K}_{\mathrm{res}}+\mathrm{K}_{\mathrm{min}}\right)$ becomes negative, $\mathrm{R}_{\mathrm{eff}}$ becomes increasingly negative, the crack being largely closed during the compression part of the load cycle. When $\left(\mathrm{K}_{\mathrm{res}}+\mathrm{K}_{\max }\right)$ becomes negative as well then $\mathrm{R}_{\text {eff }}$ will change sign and become positive; all of the load cycle being in compression. The regions of negative and positive $\mathrm{R}_{\text {eff }}$ in compression are not shown in Fig.8b as they are difficult to represent graphically.

\section{2 $K_{r e s}$ and $R_{e f f}$ in C(T) samples}

Fig.9 shows the changes in $K_{\text {res }}$ and $R_{\text {eff }}$ as the crack tip grows across CT samples. As in the ESET samples, residual stresses around the notch tip are compressive for stresses perpendicular to the weld. $K_{\text {res }}$ at the notch roots are $-5.0 \mathrm{MPa} \sqrt{\mathrm{m}}$,

-8.0 MPa $\sqrt{\mathrm{m}}$, and $-18.5 \mathrm{MPa} \sqrt{\mathrm{m}}$ for samples $87.5,125$ and $250 \mathrm{~mm}$ wide, the values increase with increasing $K_{\text {res }}$, becoming positive at long crack lengths. As in the case of the ESET samples, $K_{\text {res }}$ tends to zero at long crack lengths, with the largest sample requiring the longest crack length to become zero, reflecting the redistribution behaviour of the residual stresses as the crack length increases in the three samples. 
Fig.9(b) shows that when the crack length is small, $R_{\text {eff }}$ in CT samples is $-0.3,-1.5$ and $-3.5 \mathrm{MPa} \mathrm{m}^{1 / 2}$ for samples of $87.5,125 \mathrm{~mm}$ and $250 \mathrm{~mm}$, implying $\Delta \mathrm{K}$ is partially in compression, and $\Delta \mathrm{K}_{\mathrm{eff}}$ is significantly reduced as the crack will be partially closed for much of the load cycle. With increased crack length, $R_{\text {eff }}$ moves into tension, and tends to $\mathrm{R}=0.1$. In the biggest specimen, $R_{\text {eff }}$ tends to 0.2 as $K_{\text {res }}$ becomes significantly tensile. As in the case of Fig. $8 \mathrm{~b}$ the values of $\mathrm{K}_{\mathrm{res}}$ in the region nearest to the notch are not plotted in $9 \mathrm{~b}$ as they are either fully in compression and positive, or have very large negative values.

\section{Fatigue life predictions in welds using the closure model}

The equations introduced in [16] by the crack closure model can be used to calculate a crack opening stress level $S_{o}$ for these tests as follows.

$$
\frac{S_{o}}{S_{\max }}=A_{0}+A_{1} R+A_{2} R^{2}+A_{3} R^{3} \quad \text { for } \quad R \geq 0
$$

and

$$
\frac{S_{o}}{S_{\max }}=A_{0}+A_{1} R \quad \text { for } \quad-1 \leq R<0
$$

when $S_{o} \geq S_{\min }$. The coefficients used [15-16] were:

$$
\begin{aligned}
& A_{0}=\left(0.825-0.34 \alpha+0.05 \alpha^{2}\right)\left[\cos \left(\pi S_{\max } / 2 \sigma_{0}\right)\right]^{1 / \alpha} \\
& A_{1}=(0.415-0.071 \alpha) S_{\max } / \sigma_{0} \\
& A_{2}=1-A_{0}-A_{1}-A_{3} \\
& A_{3}=2 A_{0}+A_{1}-1
\end{aligned}
$$

For plane stress conditions, $\alpha=1$, while for plane strain conditions, $\alpha=3$. The flow stress $\sigma_{0}$ is taken to be the average between the uniaxial yield stress and uniaxial ultimate tensile strength of 2195-T8, see Table 2 in Part I. In this paper, $\alpha$ was set as the intermediate value $\alpha=1.5$. 
Then the effective stress intensity factor range $\Delta K_{\text {eff }}$ is given by

$$
\Delta K_{\text {eff }}=\frac{1-\frac{S_{o}}{S_{\max }}}{1-R} \Delta K
$$

$R_{\text {eff }}$ was used in equations (12)-(18) instead of $R$. For $R_{\text {eff }}<0$, equation (13) was used to calculate $\frac{S_{o}}{S_{\max }}$.

Crack growth rate data for parent material at three different $\mathrm{R}$ ratios of $\mathrm{R}=0.1,0.35$, 0.6 was taken from [22], These data are shown in Fig.10. $\Delta K_{\text {eff }}$ and the master curve can be calculated using the equations above. The resultant plot of da/dN Vs $\Delta \mathrm{K}_{\mathrm{eff}}$ is shown in Fig.11. The relationship of $\frac{d a}{d N}(\mathrm{~m} / \mathrm{cycle})$ with $\Delta K_{\text {eff }}(\mathrm{MPa} \sqrt{m})$ in parent material 2195-T8 can be represented as:

$$
\frac{d a}{d N}=3.0 \cdot 10^{-11}\left(\Delta K_{e f f}\right)^{4.5332}
$$

For the $100 \mathrm{~mm}$ wide ESET sample, values of $\Delta K_{\text {eff }}$ vs. crack length represented as distance from the weld centreline, was calculated for the test at $\mathrm{R}=0.6$. The results are shown in Fig.12, for the situations with and without residual stress. The line without residual stress is the normal unwelded situation. With residual stress, before a crack length of $12 \mathrm{~mm}, \Delta K_{\text {eff }}$ is reduced to $2 \mathrm{MPa} \sqrt{\mathrm{m}}$, about one quarter of $\Delta \mathrm{K}$ without residual stress. $\Delta K_{\text {eff }}$ increases rapidly after $10 \mathrm{~mm}$, merging with the line without residual stress. In Fig.13, $\Delta K_{\text {eff }}$ for the three sizes of $\operatorname{ESE}(\mathrm{T})$ samples are compared. In the $370 \times 100 \mathrm{~mm}, \Delta K_{\text {eff }}$ is much smaller than the smaller sample because the residual stress is much higher there. 


\subsection{Crack growth rates in ESE(T) samples}

Figure 14a shows the predicted crack growth rates for the 3 ESET sample sizes. There is little difference between the curves for the two smallest samples of 40 and $50 \mathrm{~mm}$ wide. The $100 \mathrm{~mm}$ wide sample is predicted to have significantly reduced crack growth rates at shorter crack lengths near the notch; the difference between all curves reduces at long crack lengths and the largest $\Delta \mathrm{K}$ values. Figure 14 (b) shows a comparison of predicted and experimental data for the smallest sample; agreement is excellent near the notch with some error (less than a factor of 2) in growth rate at the largest growth rates. The same comparison for the largest $100 \mathrm{~mm}$ wide sample is shown in figure $14 \mathrm{c}$. Here there is over prediction at both near the notch and at long crack lengths. Experimental growth rates are generally smaller than calculated ones, implying that calculated $\Delta \mathrm{K}_{\mathrm{eff}}$ is slightly greater than is found experimentally. It is interesting that the region in which the crack tip is crossing the weld line is where agreement is closest.

\subsection{Crack growth rates in $\mathrm{C}(\mathrm{T})$ samples}

Figure 15a shows the predicted crack growth data for the 3 sizes of CT samples. In many ways the CT samples show the same trends as the ESET in figure 13. There is little difference in the predicted lines for the two smallest samples. The largest sample has growth rates near the notch significantly smaller than the other two, at long crack lengths there is little difference between the 3 curves. Figure $15 \mathrm{~b}$ shows the comparison between predicted and experimental for the smallest sample. Here there is good agreement with a slight over prediction near the notch and under prediction at long crack lengths. The same comparison for the largest sample is in figure 15c. , there is an increased tendency to overpredict growth rates in the near notch region. 
There is no tendency to underpredict growth rates. At no point is the error greater than a factor of 2 .

\section{Discussion}

\subsection{Redistribution of residual stress in FE calculations}

In this work, the Mode I opening mode only was taken into account for crack propagation, so only residual stress perpendicular to crack plane was input to the finite element model. Measured residual stress parallel to the weld direction (Xdirection) is much bigger than the stress perpendicular to the weld (Y-direction) for the crack plane perpendicular to the weld, (shown in Fig.6 and Fig.7-8 in Part I [22]). For $\operatorname{ESE}(\mathrm{T})$ samples, cracks grew perpendicular to the weld, therefore residual stress parallel to the weld (X-direction) was considered. For the ESE(T) samples this was 50-120 MPa maximum depending on the sample size. Residual stresses perpendicular to the weld (Y-direction) were much smaller than this and were ignored. Local changes in stress near the notch only were necessary to achieve balance.

For $\mathrm{C}(\mathrm{T})$ samples, the biggest residual stress (X-direction) was not input to the model. The local stress minimum on the crack plane when the crack is propagating on the weld line is almost equibiaxial tension (figures $7 \& 8$ of part I [22]) and only $50 \mathrm{MPa}$. The stress maxima parallel to the weld are displaced either side of the weld line and it is unclear if crack growth will promote any stress redistribution other than to the stress perpendicular to the crack plane- which is small in any case. These stresses parallel to the crack plane were not put into the model, and may cause changes on rebalancing. In $\mathrm{C}(\mathrm{T})$ samples stresses perpendicular to the crack plane reduced by $30 \%$ on finite element balancing. This change is felt to be unrealistic and it may be that other components of stress not represented in the analysis act to maintain the balanced field at the measured values. For these samples, residual stresses in both 
directions may need to be input at the same time. Despite this change the predicted crack growth rates were in close agreement with experimental ones.

\subsection{Using $\Delta K_{\text {eff }}$ and $R_{\text {eff }}$ in crack growth predictions}

For both types of sample, the residual stresses around the notch tip were always compressive, leading to difficulties of crack initiation and reduced initial crack growth rates. The nominal $\mathrm{R}$ ratio and $\Delta \mathrm{K}_{\text {app }}$ are replaced with effective $\mathrm{R}$ ratio $R_{\text {eff }}$ and $\Delta K_{\text {eff }}$, these being a function of the local $K_{\text {res }}$. Under the measured notch compressive residual stress, $\mathrm{K}_{\text {res }}$ was calculated as $-25 M P a \sqrt{m}$ for the largest ESET sample and $-18 \mathrm{MPa} \sqrt{\mathrm{m}}$ for the largest $\mathrm{CT}$. Under external cyclic loading at $\mathrm{R}=0.1$ $\left(\mathrm{K}_{\max }+\mathrm{K}_{\mathrm{res}}\right)<0$ and the entire range of $\Delta \mathrm{K}$ is in compression. This situation can be physically interpreted as a region where crack faces are closed and no crack growth can occur. If the $R$ ratio is increased to $0.6,\left(\mathrm{~K}_{\max }+\mathrm{K}_{\mathrm{res}}\right)$ can become positive and $\Delta \mathrm{K}_{\mathrm{eff}}$ will be $>0$. Provided that $\Delta \mathrm{K}_{\mathrm{eff}}>\Delta \mathrm{K}_{\mathrm{effth}}$ the threshold for crack growth, then crack growth can occur. As crack growth proceeds, residual stress will decrease, $\mathrm{K}_{\mathrm{res}}$ and $\mathrm{R}_{\mathrm{eff}}$ become less negative and $\Delta \mathrm{K}_{\mathrm{eff}}$ gradually increases, with consequent increasing crack growth rates.

\subsection{Effects of weld microstructure and HAZ hardness}

The predictive model used here has assumed that the effects of the weld on fatigue crack growth are largely a consequence of the residual stress distribution, its size and shape in relation to the growing fatigue crack, and its effect on $\Delta \mathrm{K}_{\mathrm{eff}}$ as it grows through the weld. The effect on crack growth rate of changes in $\Delta \mathrm{K}_{\mathrm{eff}}$ has been interpreted in terms of growth rates measured on parent plate material. For the ESET sample, this assumption is valid for most of the time, as the crack spends only a short distance propagating through the weld nugget; most of the life is spent propagating 
through parent material. For CT samples, crack growth is initiated in the weld nugget, and then grows out from the nugget to thermal mechanical affected zone. In figure 11 of part I [22] there are no obvious discontinuities in crack growth rates associated with this transition in crack path, which might suggest that microstructure greatly influenced crack growth rate. dos Santos et al, [23] have measured using microtensile samples ductilities of between $20-30 \%$ on FSW nugget material. This is considerably greater than parent plate ductility and suggests that fatigue crack growth resistance will be superior in the nugget and provides a rationale for crack deviation to a weld region where growth is faster. The greatly reduced hardness values recorded in the welds in this study (figure 3 of part I [22]) support this conjecture. However, while the effects of microstructure on crack path are clear, effects of it on crack growth rate are not obvious.

A comparison of figures 14 (b) and 15 (b), showing the da/dN values for ESET and CT samples, shows that for the smallest specimens, there is little difference in growth rates in the two sample geometries, even though one is propagating in parent plate and the other is growing in nugget material first, then moves out of it to the thermal affected zone. This suggests that effects of microstructure and hardness are less

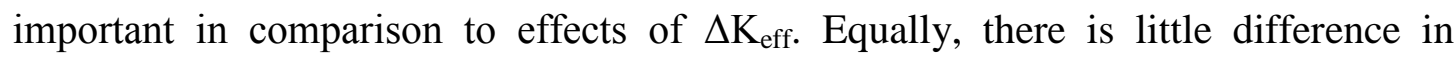
accuracy of the predictions in ESET and CT (Figures 14 and 15) samples, despite the use of parent plate data throughout.

\section{Conclusions}

(1) Experimentally measured residual stress data points can imply a residual stress field which is not self balanced; when they are put into an FE model of the sample rebalancing may result in significant changes to the measured fields. 
(2) Numerical models of residual stress redistribution with crack growth show that stresses and $\mathrm{K}_{\text {res }}$ values reduce significantly as the crack grows.

(3) For ESET and CT welded samples, the edge notch root was in a compressive residual stress field causing greatly reduced $\Delta \mathrm{K}_{\text {eff }}$ values and reduced crack growth rates.

(4) Measured fatigue crack growth rates were strongly dependent on the residual stress intensity $K_{\text {res }}$ together with the applied $R$ ratio, and the influence they jointly had on $\Delta \mathrm{K}_{\text {eff }}$ and $\mathrm{R}_{\text {eff. }}$

(5) Effects of residual stress field on fatigue crack growth rates appear to dominate over effects of microstructure and local mechanical properties; crack path appears influenced additionally by local microstructure and mechanical properties.

(6) A closure model based on calculation of $\Delta \mathrm{K}_{\mathrm{eff}}$ using a master curve of parent plate crack growth data has been successful at predicting fatigue crack growth rates in welded samples of a wide range of sizes, residual stresses and crack orientations with respect to the weld.

Acknowledgement The project was funded by the European Commission through

a Framework Programme 6 project entitled "cost effective integral structures (COINS)" under contract number AST5-CT-2006-030825. Grateful thanks to Rob Maziarz, Airbus UK for supply of FSW plates. 


\section{References}

[1] G. Pouget, A.P. Reynolds. Residual stress and microstructure effects on fatigue crack growth in AA2050 friction stir welds. International Journal of Fatigue 30 (2008) 463472.

[2] L. Fratini et al., Fatigue crack growth in 2024-T351 friction stir welded joints. Int J Fatigue (2008)

[3] Anne-Laure Lafly, Claudio Dalle Donne and et al. Role of residual stress on fatigue crack propagation of FSW 6056-T78 aluminium joints under various technologies. Materials Science Forum Vol. 519-521(July 2006) 1089-1094.

[4] S. Pasta, A.P. Reynolds, L. Frantini. Residual stress effects on fatigue crack growth in Ti-6-4 friction stir welds. Associazione Italiana Per L'Analisi Delle Sollecitazioni XXXV Convegno Nazionale, 13th-16th Sep. 2006.

[5] M.T. Milan, W.W. Bose Filho, J.R. Tarpani et al. Residual stress evaluation of AA2024T3 friction stir welded joints. Journal of Materials Engineering and Performance, 16(1) (2007): 86-92.

[6] H.F. Buechner. Weight functions for the notched bar. Z. Angewandte Mathemat. Mechan. 51 (1971), 97-109.

[7] G. Glinka and G.SHEN. Universal features of weight functions for cracks in mode I. Engineering Fracture Mechanics, Vol.40 No.6 (1991) : 1135-1146.

[8] Y.C. LAM and K.S. LIAN. The effect of residual stress and its redistribution on fatigue crack growth. Theoretical and Applied Fracture Mechanics 12 (1989) : 59-66.

[9] S.R. Daniewicz, J.A. Collins and D.R. Houser. An elastic-plastic analytical model for predicting fatigue crack growth in arbitrary edge-cracked two-dimensional geometries with residual stress. Fatigue, Feb. 1994, Vol 16, 123-133.

[10] Yong-Bok Lee et al. Effects of redistributing of residual stress on the fatigue behavior of SS330 weldment. Int. J. Fatigue, Vol 20. No.8 (1998), 565-573.

[11] J.E. LaRue, S.R. Daniewicz. Predicting the effect of residual stress on fatigue crack growth. Int. J. Fatigue, 29 (2007), 508-515.

[12] C Dalle Donne, G Biallas, T Ghidini, G Raimbeaux. "Effect of weld imperfections and residual stresses on the fatigue crack propagation in friction stir welded joints", In: Proceedings of the second international symposium on friction stir welding, Gothenburg, Sweden; June 2000.

[13] C Dalle Donne, G Raimbeaux. "Residual stress effects on fatigue crack propagation in friction stir welds". In: Tenth international conference on fatigue ICF10, Hawaii, USA; 2001.

[14] D.V. Nelson. Effects of residual stress on fatigue crack propagation. Residual stress effects in fatigue, ASTM STP 776, American Society for Testing and Materials, 1982, pp 172-194.

[15] J.C. Newman. A crack opening stress equation for fatigue crack growth. International Journal of Fracture, 1984(24), 131-135.

[16] J.C. Newman. Fratran-II-A fatigue crack growth structural analysis program. NASA Technical memorandum 104159, Feb. 1992.

[17] Finite element analysis of plasticity-induced fatigue crack closure: an overview. Engineering Fracture Mechanics 71 (2004): 149-171.

[18] Elber W. The significance of fatigue crack closure damage tolerance in aircraft structures. In: ASTM STP 486, 1971: 230-242.

[19] R. G. Forman, V. E. Kearney, R. M. Engle, Numerical Analysis of Crack Propagation Cyclic-Loaded Structures, Trans. AMSE, J. bas. Engng, 893 (September 1967).

[20] ABAQUS Version 6.7.

[21] Ronald Krueger. The virtual crack closure technique: history, approach and applications. NASA/CR-2002-211628. 
[22] Y E Ma, T Fisher P E Irving "Size effects on residual stress and fatigue crack growth in friction stir welded 2195 T8 aluminium Part I : experiments" submitted to International Journal of Fatigue October 2010.

[23] J. dos Santos, GKSS report to COINS project May 2008. 


\section{Tables}

Table 1 Sample dimensions $\mathrm{C}(\mathrm{T})$ and $\operatorname{ESE}(\mathrm{T})$

\begin{tabular}{lccc}
\hline Relationship with weld & Type & $\begin{array}{c}\text { Sample size }(\mathrm{mm}) \\
\text { length x width }\end{array}$ & $\mathrm{W}(\mathrm{mm})$ \\
\hline \multirow{2}{*}{ Crack parallel to weld } & \multirow{2}{*}{ C(T) } & $84 \times 87.5$ & 70 \\
\cline { 3 - 4 } & & $120 \times 125$ & 100 \\
\hline \multirow{2}{*}{$\begin{array}{c}\text { Crack perpendicular to } \\
\text { weld }\end{array}$} & $\mathrm{ESE}(\mathrm{T})$ & $240 \times 250$ & 200 \\
\cline { 3 - 4 } & & $148 \times 40$ & 40 \\
\cline { 3 - 4 } & & $370 \times 100$ & 50 \\
\hline
\end{tabular}




\section{Figures}

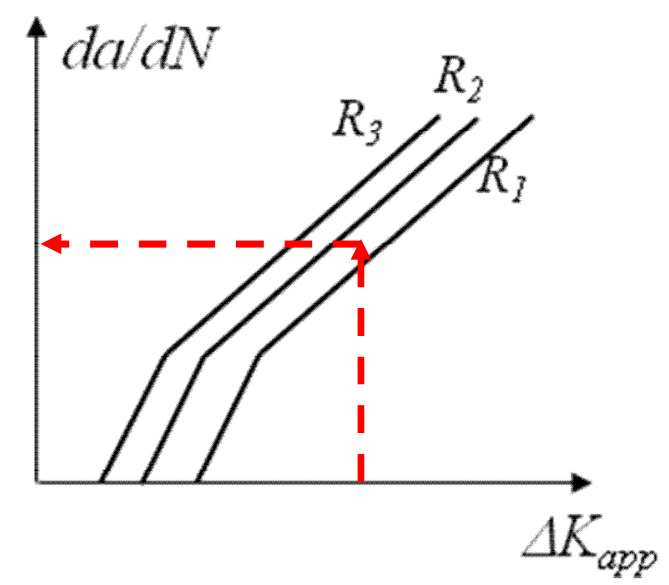

Fig.1 Superposition approach for calculation of fatigue crack growth rates under residual stress fields

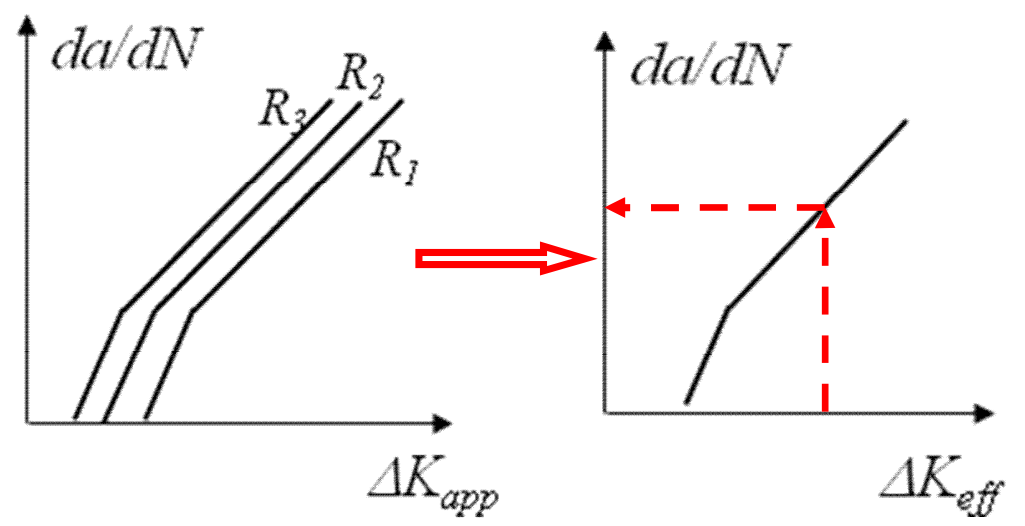
(a)da/dN versus $\Delta K_{a p p}$
(b)da/dN versus $\Delta K_{\text {eff }}$

Fig. 2 Crack closure concept for calculation of fatigue crack growth rates in residual stress fields.
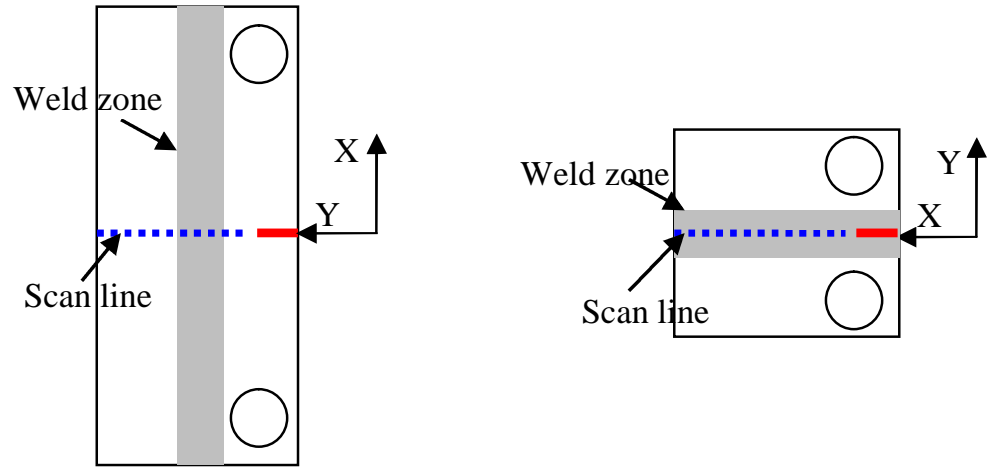

Fig.3 ESE(T) and C(T) samples 


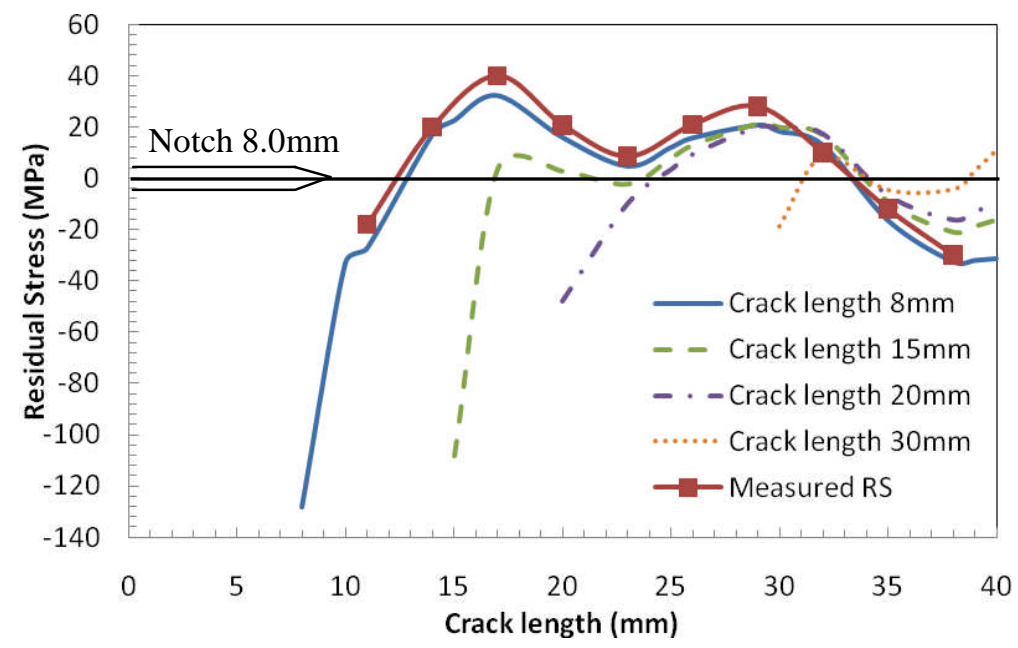

Fig.4 Calculated effects of crack growth on residual stress distribution in 148x40 ESE(T) sample

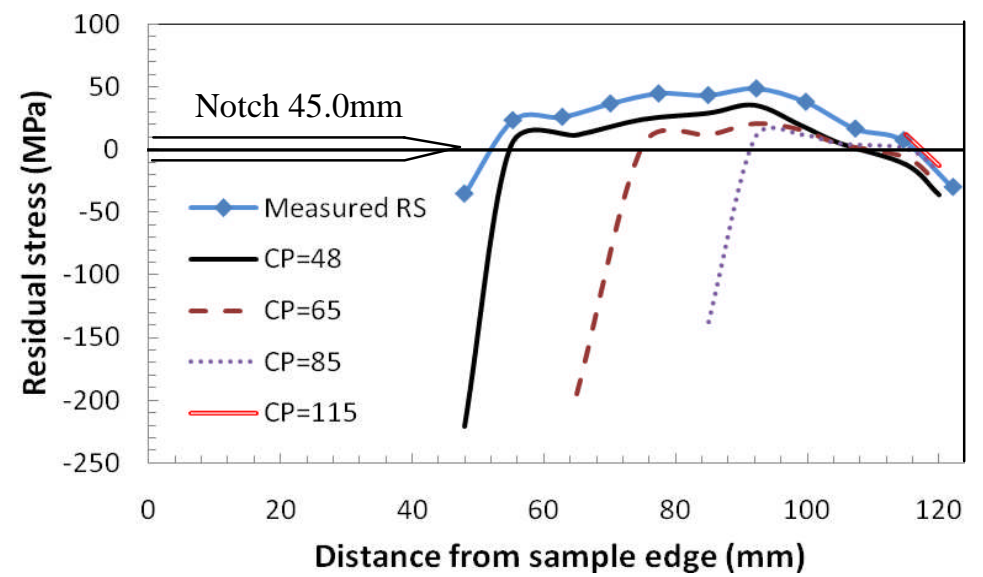

Fig.5 Calculated effects of crack growth on residual stress fields in $125 \times 120 \mathrm{C}(\mathrm{T})$ sample $(\mathrm{CP}=48$ is crack tip position at $48.0 \mathrm{~mm}$ away from sample edge, the others are the same)

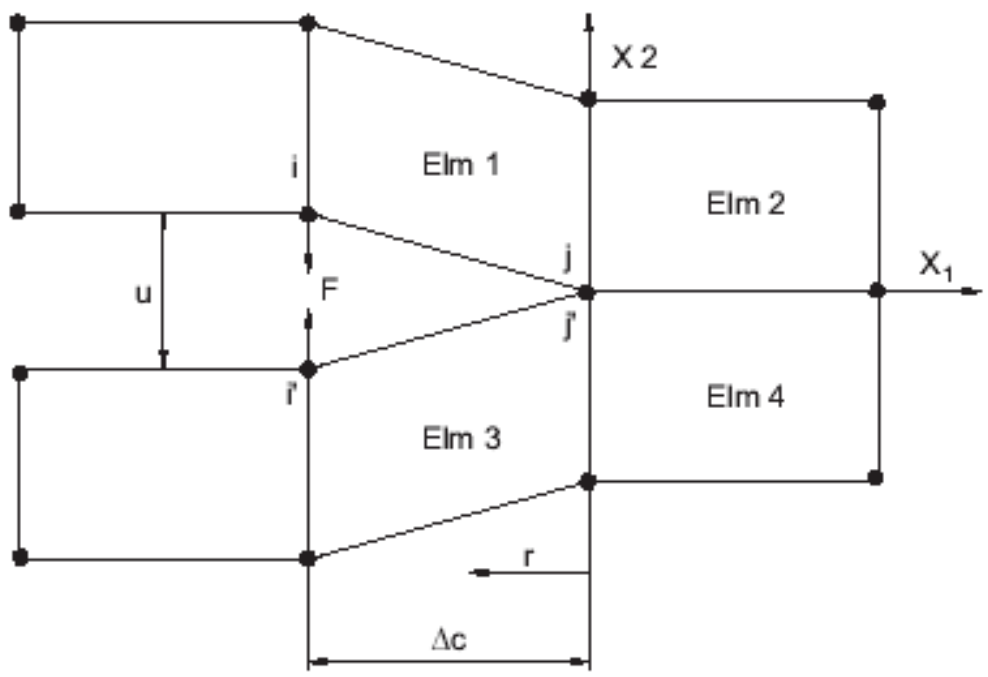

Fig.6 Virtual crack closure technique 


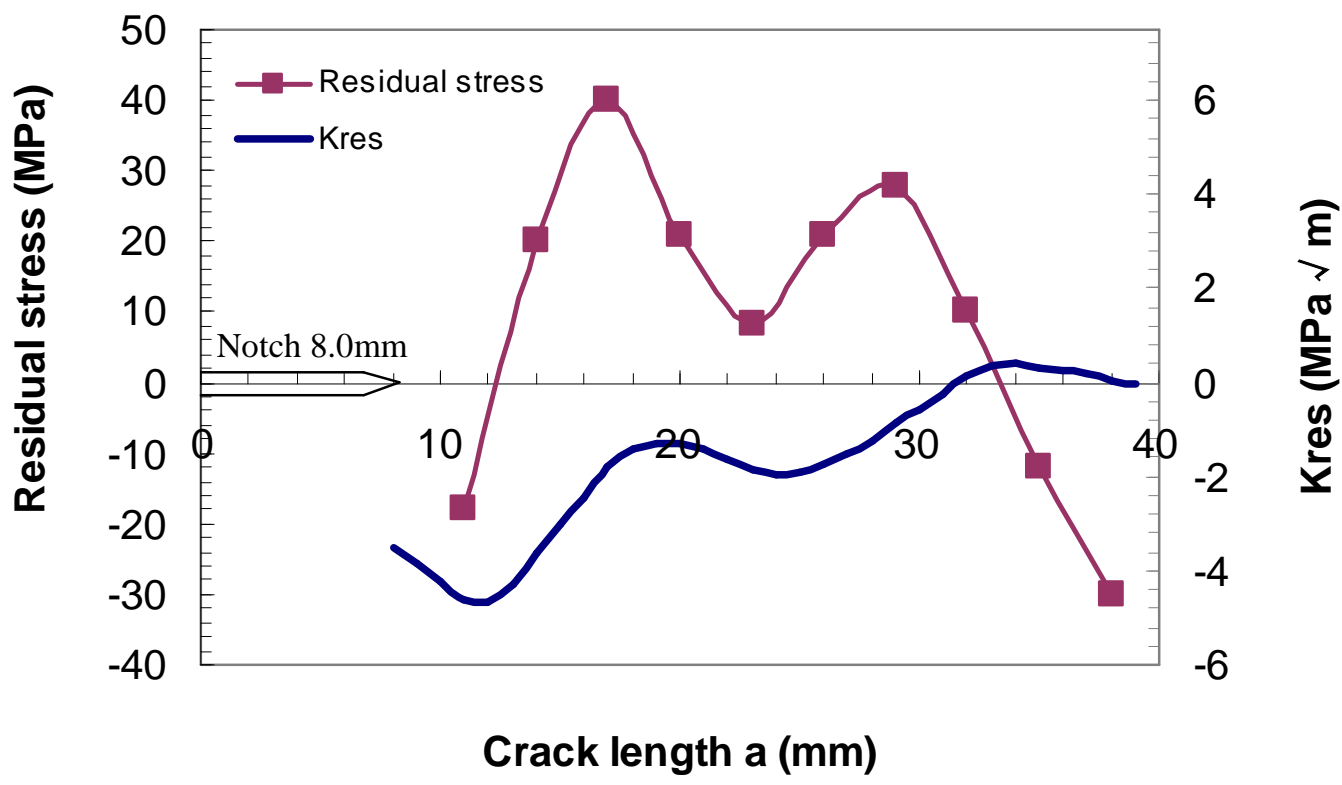

Fig 7(a) Calculated $K_{\text {res }}$ and the measured residual stress profile in the smallest ESE(T) sample $(148 \times 40 \mathrm{~mm})$

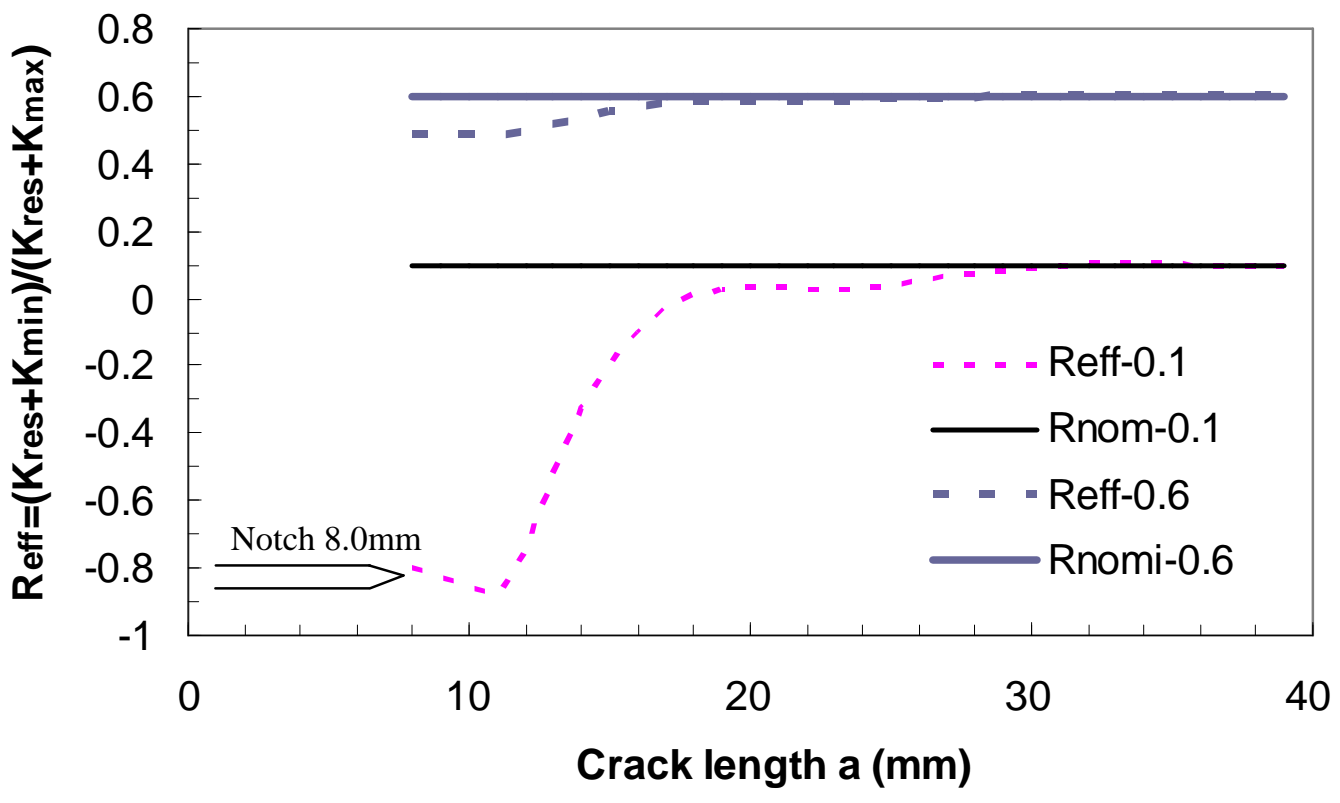

Fig 7(b) Changes in $R_{\text {eff }}$ with crack length in the smallest $\operatorname{ESE}(\mathrm{T})$ sample (148x40 mm) with external load cycle of $\mathrm{R}=0.1$ and $\mathrm{R}=0.6$

Fig $7 K_{\text {res }}$ and $R_{\text {eff }}$ in the smallest $\operatorname{ESE}(\mathrm{T})$ sample (148x40) 


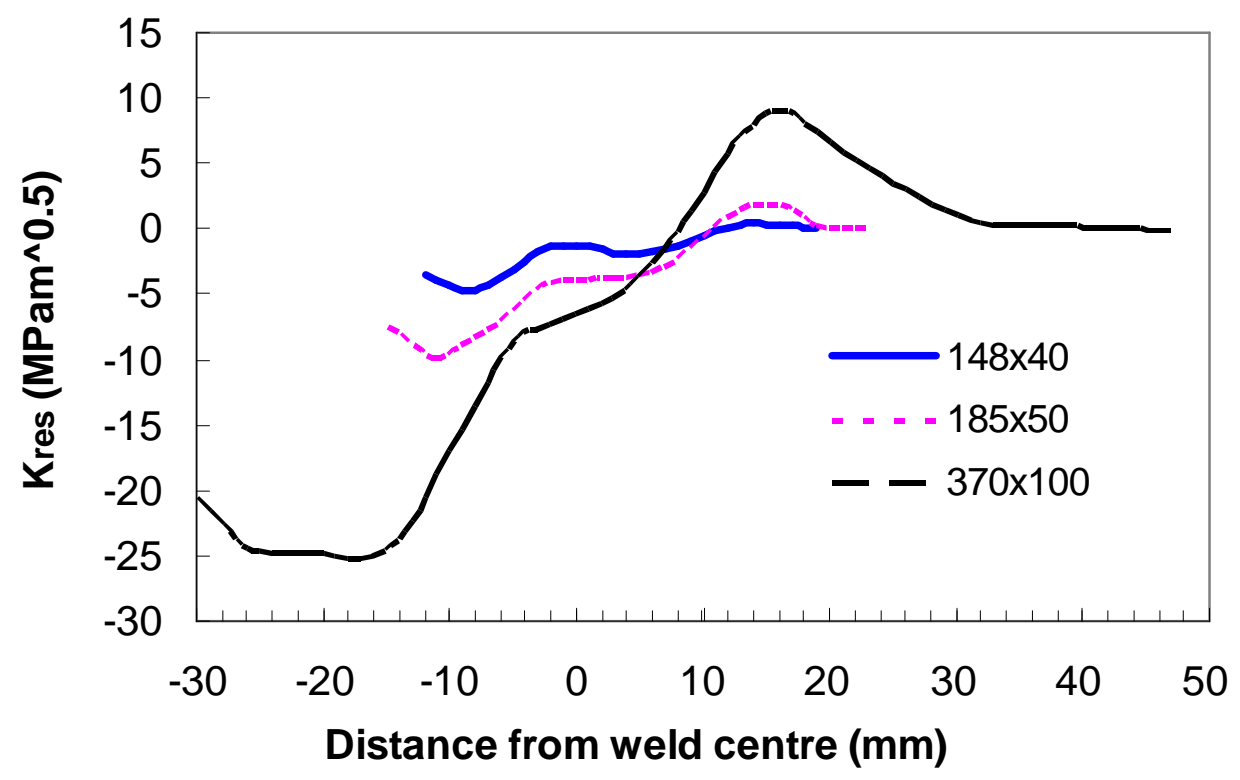

(a) $K_{\text {res }}$ changes with crack tip position across the weld line in three $\operatorname{ESE}(\mathrm{T})$ sample sizes

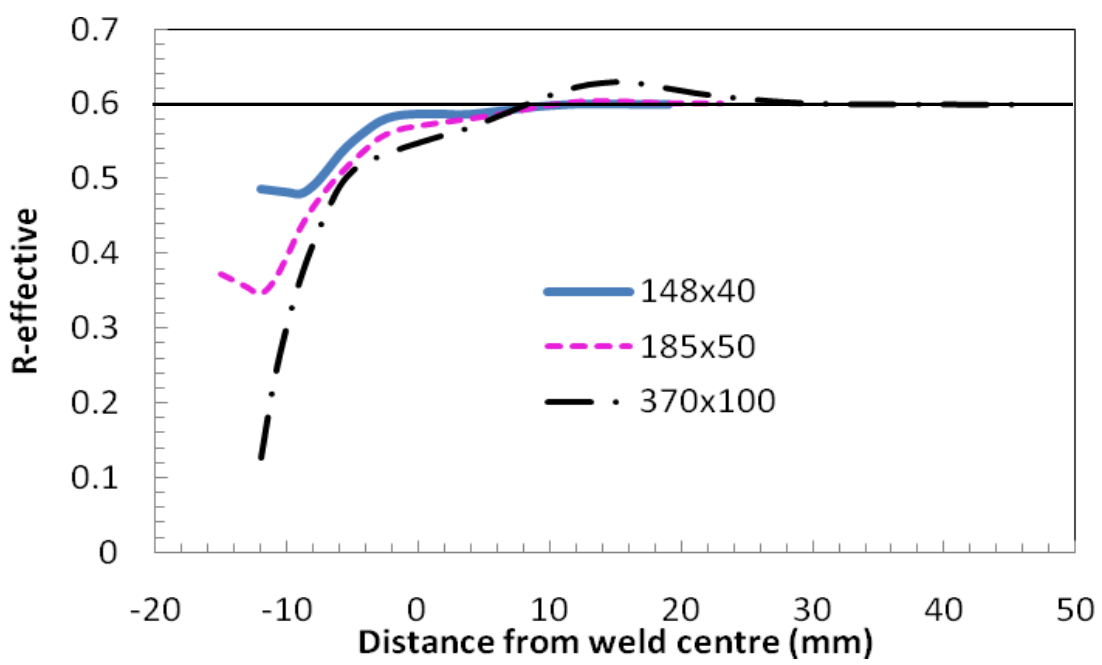

(b) Changes in $R_{\text {eff }}$ with crack tip position in three sizes of $\operatorname{ESE}(\mathrm{T})$ samples

Fig $8 K_{r e s}$ and $R_{\text {eff }}$ changes with crack tip position in three sizes of ESE(T) samples 


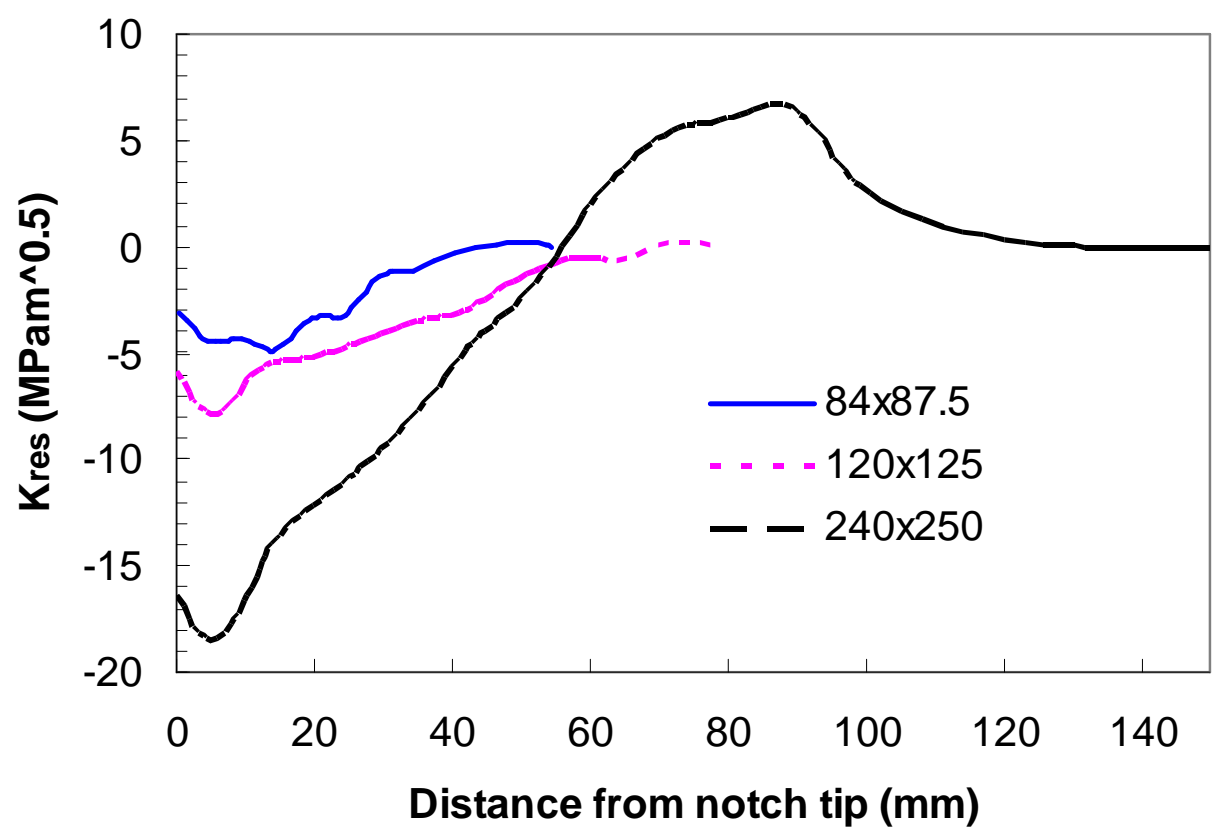

(a) Changes in $K_{\text {res }}$ with crack tip position in three sizes of C(T) samples

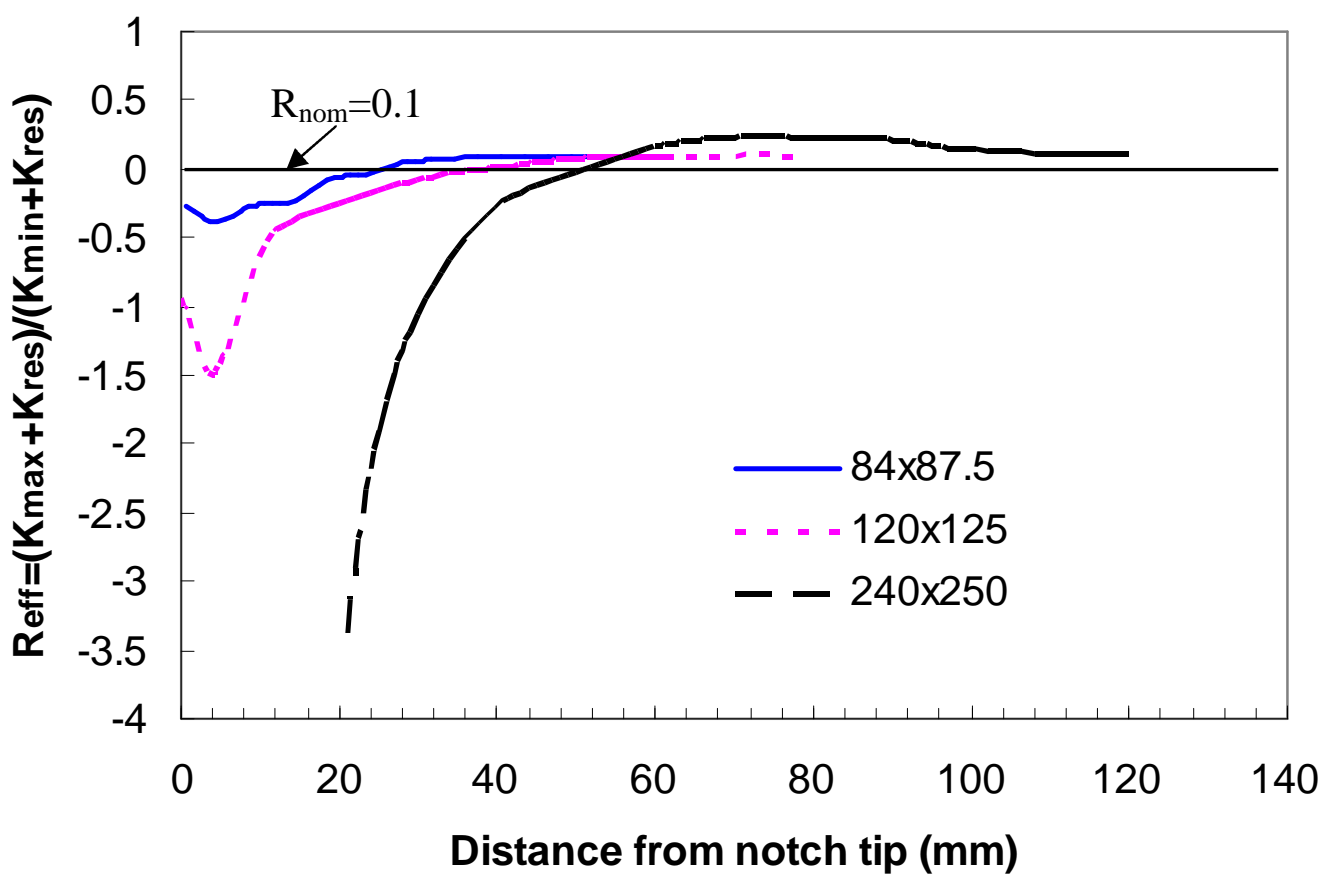

(b) Changes in $R_{\text {eff }}$ with crack tip position in three sizes of C(T) samples

Fig $9 K_{r e s}$ and $R_{\text {eff }}$ for three sizes of C(T) samples 


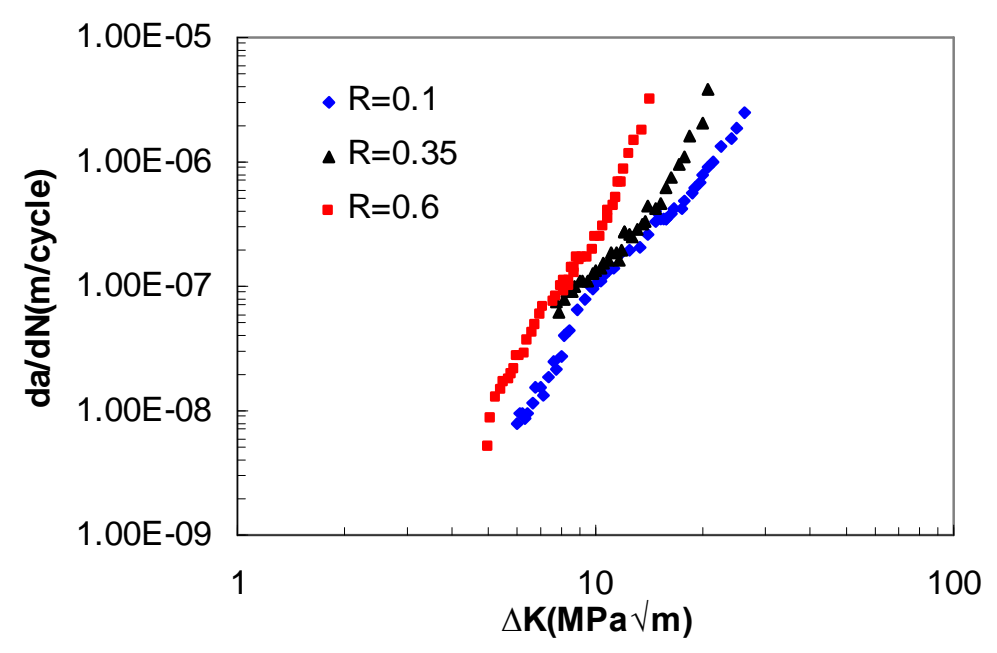

Fig. 10 Crack growth rates Vs $\Delta \mathrm{K}$ at $\mathrm{R}=0.1,0.35,0.6$ in $8.0 \mathrm{~mm}$ thick 2195 - $\mathrm{T} 8$ parent material.

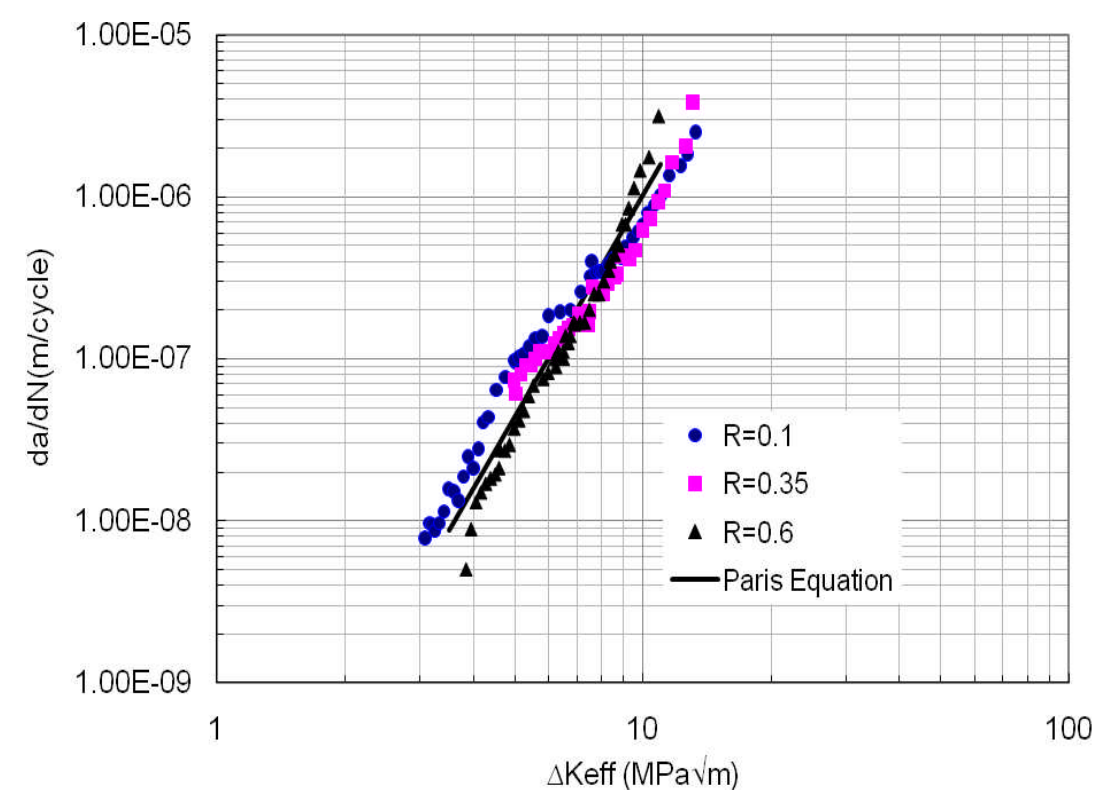

Fig. 11 "Master curve" of $8.0 \mathrm{~mm}$ thick 2195-T8 Parent material derived from Fig 10 data 


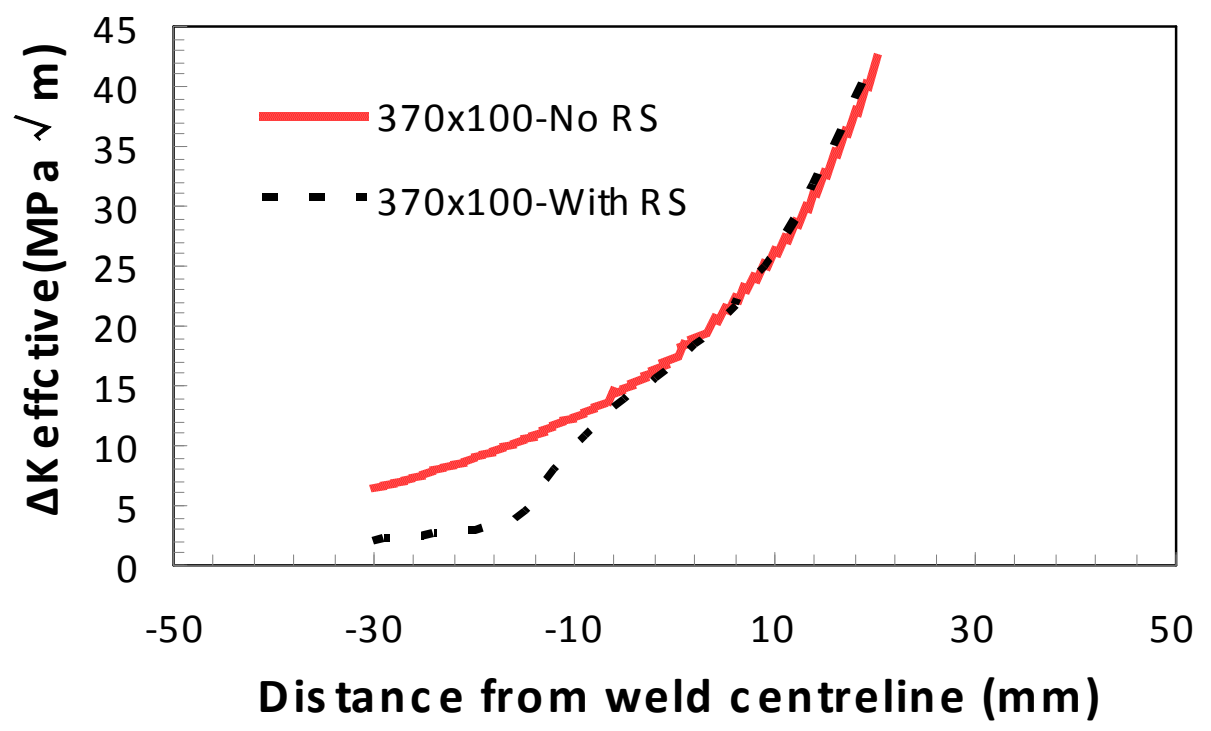

Fig.12 Comparison of $\Delta K_{\text {eff }}$ with and without residual stress in 370x100 mm ESET samples with external loading at $\mathrm{R}=0.6$

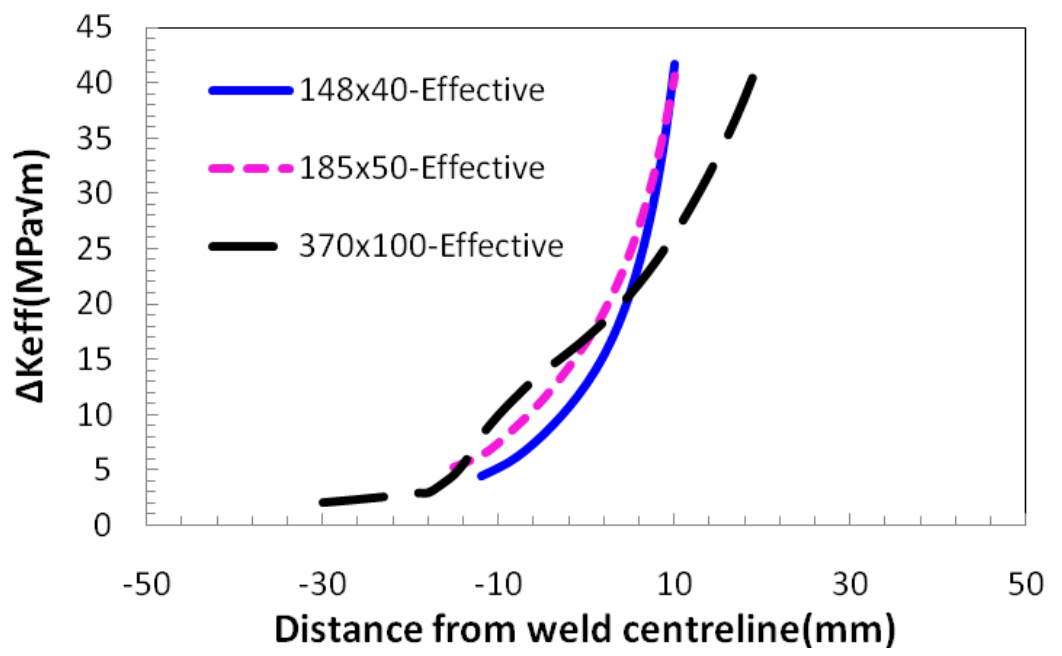

Fig.13 changes in $\Delta K_{\text {eff }}$ with crack tip position in all three sizes of ESE(T) sample with external loading at $\mathrm{R}=0.6$ 


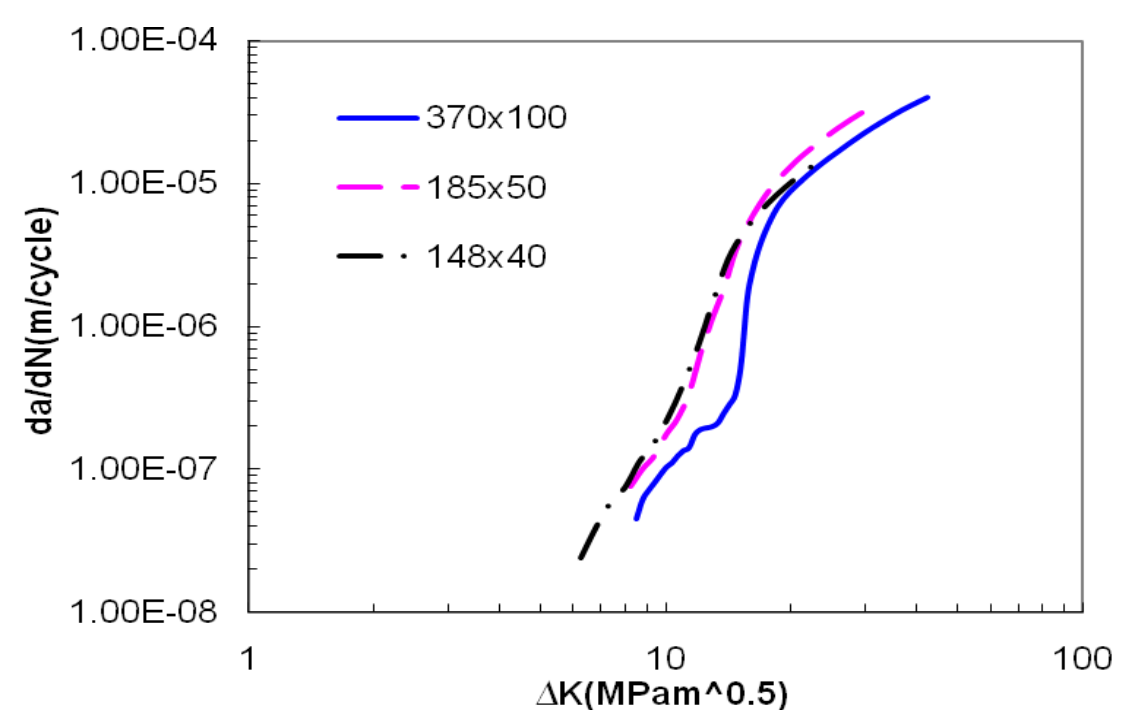

Fig.14(a) Predicted crack growth rate da/dN Vs $\Delta \mathrm{K}_{\text {app }}$ for three size ESE(T) samples with external loading at $\mathrm{R}=0.6$

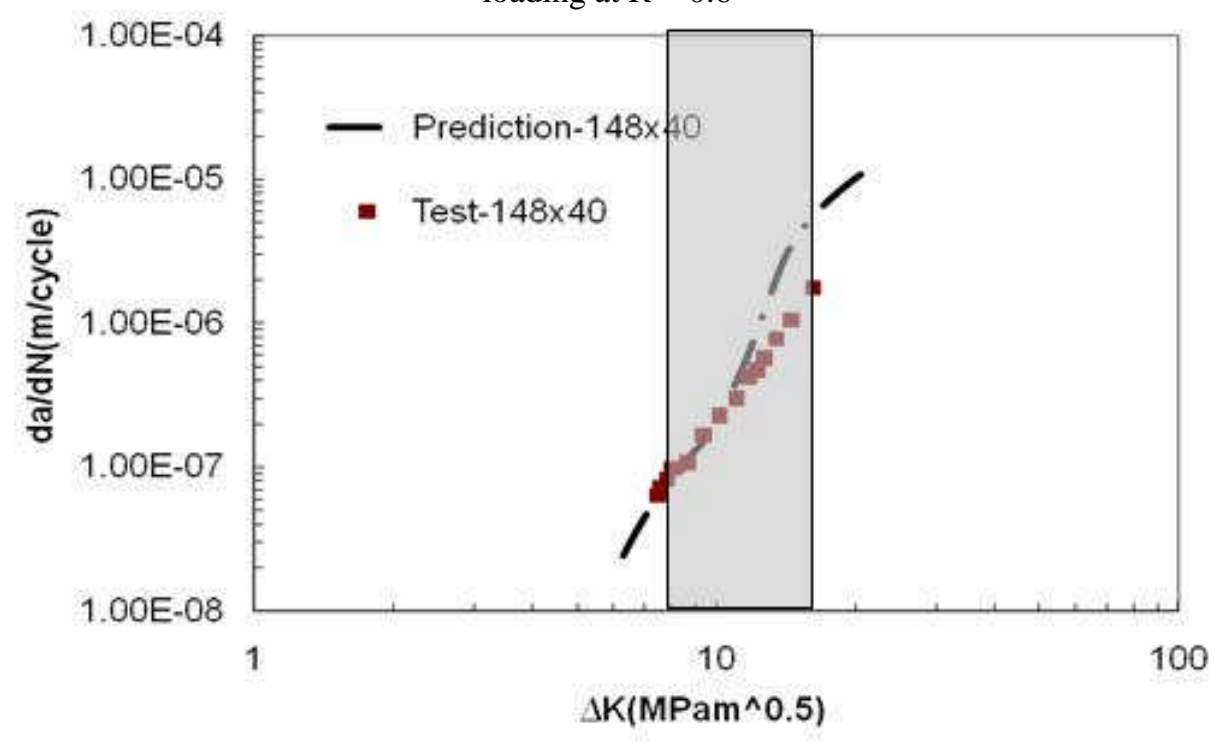

Fig.14 (b) Comparison of predicted and experimental fatigue crack growth rates for the smallest $\operatorname{ESE}(\mathrm{T})$ sample $(148 \times 40)$ at $\mathrm{R}=0.6$; shaded area denotes the extent of the weld nugget 


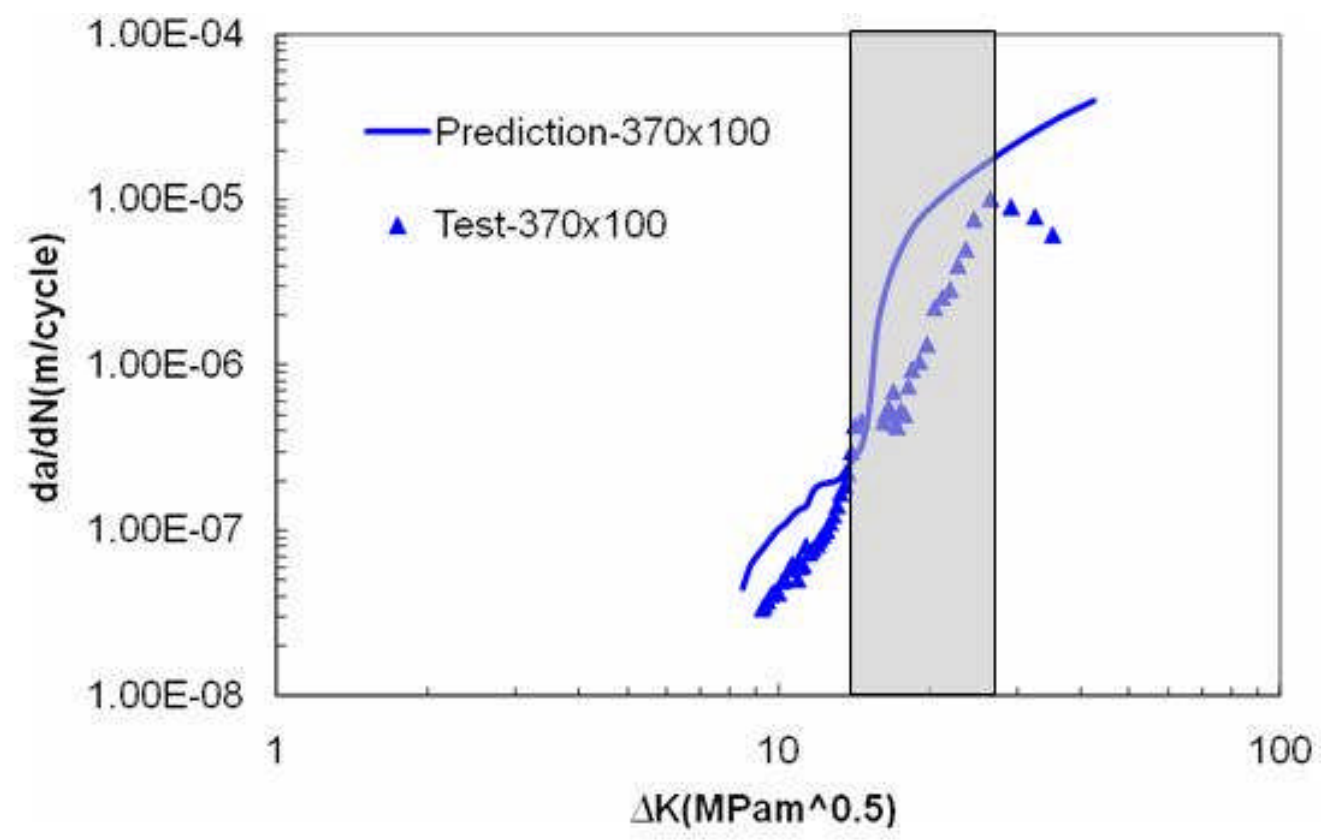

Fig.14 (c) Comparison of predicted crack growth rates with experimental ones for the largest $\operatorname{ESE}(\mathrm{T})$ sample $(370 \times 100 \mathrm{~mm})$ at $\mathrm{R}=0.6$; shaded area denotes the extent of the weld nugget

Fig. 14 Predictions and experimental results in $\operatorname{ESE}(T)$ samples at $R=0.6$ 


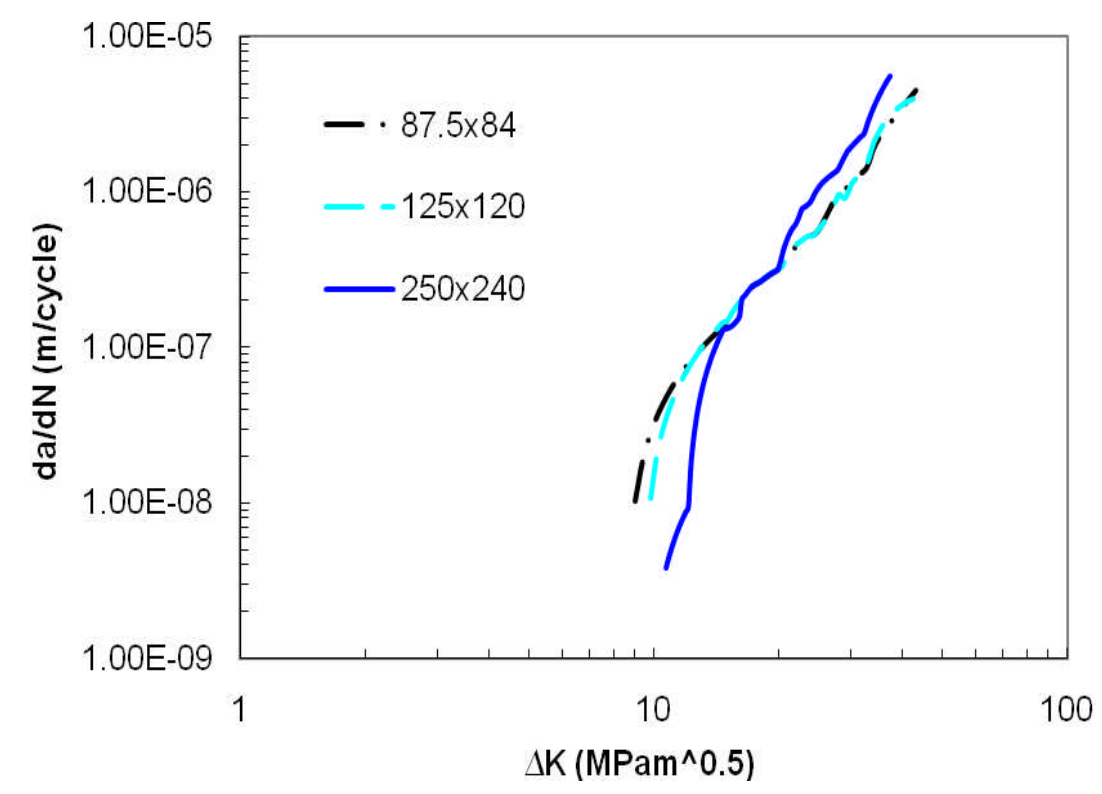

Fig.15 (a) Comparison of predicted crack growth rate da/dN for three sizes of $\mathrm{C}(\mathrm{T})$ samples

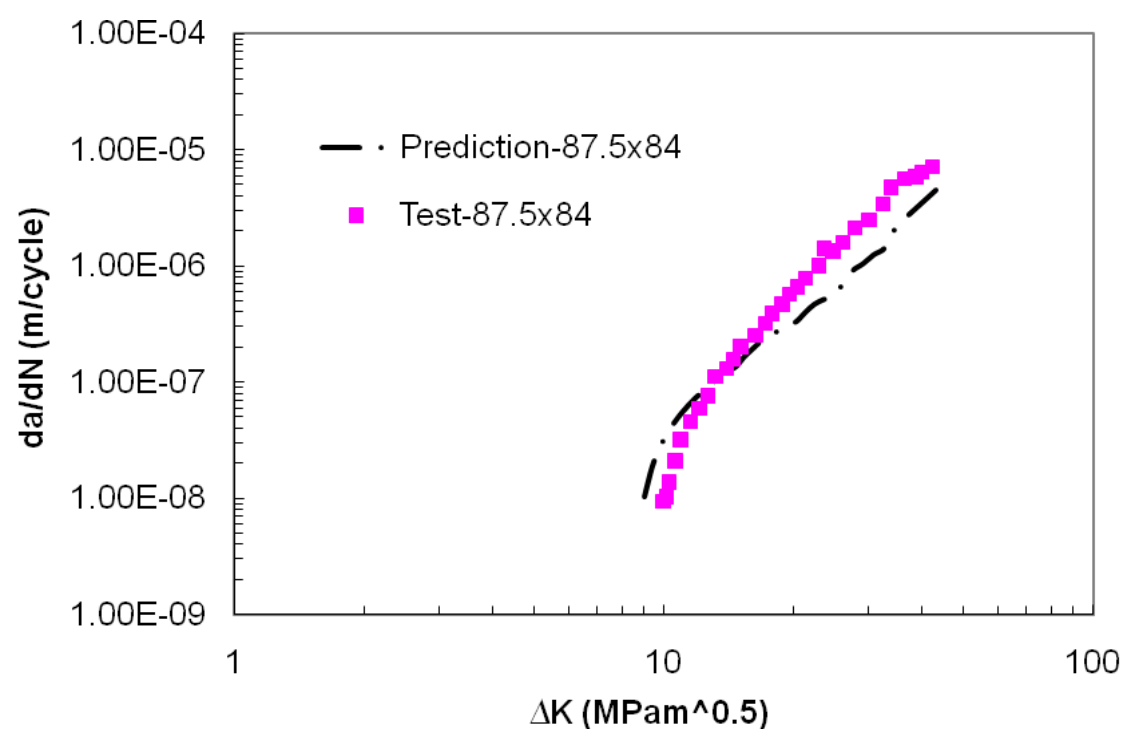

Fig.15 (b) Comparison of predicted crack growth rates with experimental ones for the smallest $\mathrm{C}(\mathrm{T})$ sample $(87.5 \times 84 \mathrm{~mm})$ tested at $\mathrm{R}=0.1$ 


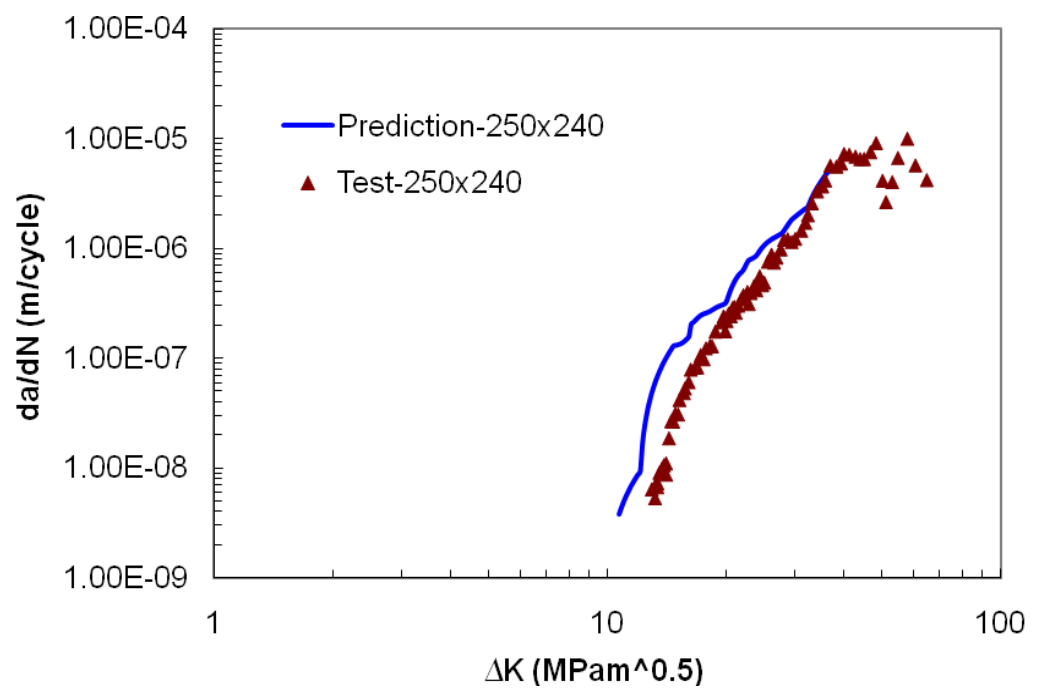

Fig.15 (c) Comparison of predicted crack growth rates with experimental ones for the largest $\mathrm{C}(\mathrm{T})$ sample $(250 \times 240 \mathrm{~mm})$ at $\mathrm{R}=0.1$

Fig.15 Predictions and experimental results in $\mathrm{C}(\mathrm{T})$ samples at $\mathrm{R}=0.1$ 